\title{
SOBREVIVENCIA DE Vibrio mimicus EN LA CLARA Y EN LA YEMA DEL HUEVO DE TORTUGA LORA (Lepidochelys olivacea) ${ }^{1}$
}

\author{
Mónica Pereira-Zamora², Eric Wong-González ${ }^{2}$
}

\begin{abstract}
RESUMEN
Sobrevivencia de Vibrio mimicus en la clara y en la yema del huevo de tortuga lora (Lepidochelys olivacea). En el año 2000, en el Centro Nacional de Ciencia y Tecnología de Alimentos de la Universidad de Costa Rica, se estudió la sobrevivencia de Vibrio mimicus en la clara y yema del huevo de tortuga lora. Se inocularon muestras de clara o yema con el vibrio (aproximadamente $2,5 \times 10^{4} \mathrm{UFC} / \mathrm{g}$ ) y se determinó la carga inicial y final al cabo de 18 horas de incubación a $25^{\circ} \mathrm{C}$. De forma análoga se trabajó una muestra control en agua peptonada alcalina (APA) como medio óptimo de crecimiento para el vibrio y una muestra control de clara o yema sin inocular. Con los recuentos obtenidos se calcularon los incrementos promedio $\left(\log _{10} \mathrm{UFC} / \mathrm{g}\right)$. En la clara los resultados mostraron incrementos similares para la muestra sin inocular, muestra inoculada y control en APA $(4,67,5,24$ y 5,49 respectivamente). El crecimiento, en la muestra de clara sin inocular, se atribuyó a contaminación proveniente de la cáscara al abrir el huevo. En el caso de la yema, al comparar los incrementos observados para la muestra inoculada $(4,42)$ y el control en APA $(5,21)$, no se encontraron diferencias significativas, sin embargo, al comparar estos dos valores contra el de la muestra sin inocular $(0,00)$, la diferencia fue evidente. En este caso se consideró que es menos probable que la contaminación de la cáscara llegue a la yema al abrir el huevo. Los resultados de esta investigación muestran que la clara y la yema de huevo de tortuga lora constituyen medios de cultivo adecuados para la reproducción de V. mimicus.
\end{abstract}

Palabras clave: Patógenos acuáticos, inocuidad, crecimiento, control, contaminación.

\begin{abstract}
Survival of Vibrio mimicus in the white and the yolk of lora turtle eggs (Lepidochelys olivacea). The objective of this research project, performed at the Centro Nacional de Ciencia y Tecnología de Alimentos in 2000, consisted of determining the survival of Vibrio mimicus in the white and yolk of Lora turtle eggs. This was done by inoculating samples of white or yolk with the vibrio (approximately $2.5 \mathrm{x}$ $10^{4} \mathrm{CFU} / \mathrm{g}$ ) and determining its count before and after an incubation period of $18 \mathrm{~h}$ at $25^{\circ} \mathrm{C}$. Same procedure was applied to a control sample of alkaline peptone buffer (APB) as an optimum media for the growth of the bacteria, and to a non inoculated sample of white or yolk. Data collected was used to calculate the average increase in the counts $\left(\log _{10} \mathrm{UFC} / \mathrm{g}\right)$ for each one of the samples analyzed. In the case of the egg white, results demonstrate similar increases in the counts for the non inoculated, inoculated and APB samples (4.67, 5.24 and 5.49 respectively). Growth on the non inoculated sample was explained in terms of possible contamination from the shell when the egg was opened. For the yolk, no difference was observed when comparing the increase found in the inoculated sample (4.42) against the one found for the APB sample (5.21), however, these two values were significantly different from the increase determined for the non inoculated sample (0.00). In this case, contamination from shell to yolk when opening the egg was considered less probable. Results of this research project demonstrate that lora turtle egg white and yolk are appropriate media for growth of $V$. mimicus.
\end{abstract}

Keywords: Aquatic pathogen, food safety, growth, control, contamination.

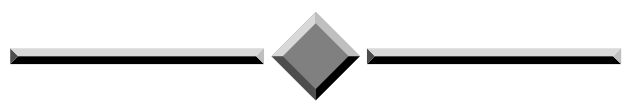

\footnotetext{
Recibido: 23 de octubre, 2007. Aceptado: 26 de agosto, 2008. Tesis para optar por el grado de licenciada en Tecnología de Alimentos.

2 Escuela de Tecnología de Alimentos, Centro Nacional de Ciencia y Tecnología de Alimentos, Universidad de Costa Rica, San José, Costa Rica.mpereira@griffithlaboratories.com; eric.wong@ucr.ac.cr
} 


\section{INTRODUCCIÓN}

El Vibrio mimicus es una bacteria que puede causar diarrea tras el consumo de alimentos que lo contienen (Hackney y Dicharry 1988). La gastroenteritis causada por este microorganismo se caracteriza por síntomas como diarrea, náuseas, vómitos, calambres y fiebre (Shandera et al. 1983), habiendo Chowdhury et al. (1989) y Sanyal et al. (1983) registrado trastornos intestinales adicionales. Se han descrito varios brotes de gastroenteritis asociados con el consumo de mariscos contaminados con V. mimicus, demostrando la importancia de esta bacteria para la salud pública (Alam et al. 1996).

Los miembros del género Vibrio tienen como hábitat natural las aguas costeras y los esteros, y aquellos microorganismos causantes de esta enfermedad se encuentran naturalmente en estos ambientes y, por lo tanto, afectan la calidad sanitaria de los mariscos frescos. García y Antillón (1990), comprobaron la presencia de vibrios enteropatógenos: V. parahaemolyticus, $V$. fluvialis, V. damsela y V. furnisii, en cieno del Golfo de Nicoya, Puntarenas, Costa Rica. De acuerdo con Chowdhury et al. (1989) y Alam et al. (1996) un alto porcentaje de las cepas de V. mimicus, aisladas de ambientes acuáticos, juegan un papel significativo como causantes de enfermedades intestinales.

Por medio de estudios de la ecología del V. mimicus se ha demostrado que vive de preferencia en aguas saladas con una concentración salina de 4\%. Esta bacteria presenta variaciones estacionales que se relacionan con la temperatura del agua observándose los mayores recuentos cuando la temperatura se encuentra entre $20^{\circ} \mathrm{C}$ y $25^{\circ} \mathrm{C}$, mientras que no es posible aislarla cuando la temperatura es inferior a $10^{\circ} \mathrm{C}$ (Chowdhury et al. 1989). Dada la reciente reclasificación, no se tiene mucha información sobre las condiciones adecuadas para el crecimiento y sobrevivencia de esta bacteria. Antes del año de 1981 el V. mimicus se clasificaba como $V$. cholerae, por lo que se ha utilizado la información disponible para este último como una guía en las investigaciones que involucran al $V$. mimicus. La temperatura óptima de crecimiento del V. cholerae está comprendida entre $30^{\circ} \mathrm{C}$ y $37^{\circ} \mathrm{C}$ y su intervalo óptimo de $\mathrm{pH}$ es de 7,6 a 8,6 (Barua 1992).

Entre los años 1991 y 1994 se reportaron, en Costa Rica, 33 casos de diarrea por V. mimicus indistinguible de la ocasionada por el V. cholerae, produciendo todas las cepas la toxina colérica (Campos et al. 1996). Con base en diversas evidencias, se determinó que el consumo de huevos de tortuga crudos tiene un papel importante como vehículo de transmisión de la enfermedad. Se encontraron, además, cepas capaces de producir la toxina colérica en un $31 \%$ de los nidos, en un $5 \%$ de los huevos y en un $6,4 \%$ de las muestras de arena recolectadas en época de arribada de la tortuga lora (Acuña et al. 1999). Acuña et al. (1999) determinaron que los huevos de tortuga lora se contaminan con $V$. mimicus al entrar en contacto con la arena del nido que constituye la principal fuente de esta bacteria.

Está bien demostrado que el V. mimicus contamina los huevos de tortuga in situ, por lo que éste debe ser destruido o reducido mediante tratamientos directos sobre el alimento, de tal manera que permitan garantizar su calidad microbiológica. En ese sentido, resulta importante, antes de diseñar alternativas para su eliminación, conocer si los componentes del huevo, por sí solos, tienen un efecto inhibitorio sobre el microorganismo.

Aunque existen datos sobre la composición química del huevo de tortuga lora se conoce muy poco sobre los componentes del huevo en otras especies de tortuga marina, lo que dificulta realizar comparaciones entre diferentes especies. Diversos factores fisiológicos permiten comparar los huevos de reptiles con los de aves, y dado que el huevo de gallina ha sido ampliamente estudiado y la información disponible es numerosa y detallada, la comparación con éste es frecuente en estudios sobre huevos de tortuga (Acuña 1980, Mora 1995).

En el huevo de tortuga lora la cáscara representa un $4 \%$ de su peso, la clara un $38 \%$ y la yema un $58 \%$ (Mora 1995). Con respecto a estos valores se puede afirmar que la yema representa más de la mitad de la masa del huevo de tortuga, mientras que en el huevo de gallina la clara es el componente mayoritario (57\%). De acuerdo con Mora (1995), el huevo de tortuga tiene una mayor humedad, en todos sus componentes, que el huevo de gallina.

Es ampliamente conocido el efecto inhibitorio de la clara del huevo de gallina sobre el crecimiento bacteriano. Diversos autores (Frazier y Westhoff 1993) 
señalan que ésta constituye un medio inapropiado para el crecimiento de muchos microorganismos por los factores antimicrobianos presentes: la apoproteína, la avidina, factores antiproteolíticos e inhibidores enzimáticos, la conalbúmina, la lisozima y el elevado $\mathrm{pH}$ $(9,40)$ que se alcanza durante el almacenamiento. Por el contrario, la yema es considerada un medio rico porque en ella se concentran la mayoría de nutrientes necesarios para el desarrollo del embrión (Belitz 1988). Se desconoce si estos factores están presentes en la clara o la yema del huevo de tortuga, lo que justifica el estudio de sobrevivencia del V. mimicus en dichos componentes. Esto generaría información valiosa que permita definir, de una forma más pertinente, los tratamientos que pueden aplicarse a los huevos para garantizar su inocuidad.

\section{MATERIALES Y MÉTODOS}

El trabajo experimental se llevó a cabo en el año 2000, en el Laboratorio de Microbiología del Centro Nacional de Ciencia y Tecnología de Alimentos (CITA), localizado en la Ciudad Universitaria Rodrigo Facio de la Universidad Costa Rica.

Los huevos de tortuga lora se obtuvieron del Refugio Nacional de Fauna Silvestre Ostional, ubicado en la costa del Pacífico en Ostional, Santa Cruz, Guanacaste (clima tropical en época lluviosa), y fueron recolectados durante los tres días siguientes después de declarada la arribada en el año 2000, ya que éstos son los que se comercializan legalmente. La recolección de la muestra la llevó a cabo el biólogo del refugio, quien en las mañanas siguientes a la arribada siguió el procedimiento de recolección normal: se escarbaron los nidos, los huevos se colocaron en bolsas plásticas limpias y se cerraron. Para su transporte al laboratorio, los huevos se colocaron en una hielera a una temperatura entre $5-10^{\circ} \mathrm{C}$ por un período de $10 \mathrm{~h}$. Una vez en el laboratorio se refrigeraron $\left(5-7^{\circ} \mathrm{C}\right)$ y se utilizaron y/o analizaron en menos de $72 \mathrm{~h}$.

La cepa de $V$. mimicus que se usó para la inoculación artificial de los huevos, fue obtenida de la bacterioteca del Instituto Costarricense de Investigación y Enseñanza en Nutrición y Salud (INCIENSA), corresponde al códigoT4, es no toxigénica $\left(\operatorname{ctx} \mathrm{A}^{-}\right)$y fue aislada en Costa Rica de huevos de tortuga lora. Esta cepa fue mantenida en medio Cary-Blair durante todo el estudio. Dos días antes de realizar las pruebas, se tomó una asada de este medio y se suspendió en caldo infusión cerebro - corazón (CICC) y después de $18-24 \mathrm{~h}$ de incubación a $37^{\circ} \mathrm{C}$ se pasó a tubos con agar tripticasa - soya inclinado (ATS), los cuales se incubaron a $37^{\circ} \mathrm{C}$ para obtener el cultivo fresco. El inóculo se preparó a partir del cultivo fresco con 18 $\mathrm{h}$ de incubación tomando asadas que se suspendieron en solución salina al 0,85\% cuya turbidez se comparó con el patrón de Mc.Farland \#05 (1,5 x 10 $\left.10^{8} \mathrm{UFC} / \mathrm{ml}\right)$. Se confirmó la viabilidad del inóculo, realizando una prueba de crecimiento en agar TCBS.

Para los recuentos de $V$. mimicus se tomaron $10 \mathrm{~g}$ de clara o yema y se homogenizaron en $90 \mathrm{ml}$ de agua peptonada alcalina (APA). A partir de esta solución se hicieron diluciones decimales seriadas en APA. De cada dilución se inoculó $0,1 \mathrm{ml}$ por el método de esparcimiento en placas con agar TCBS, por duplicado, y se incubaron a $37^{\circ} \mathrm{C}$ durante $18-24 \mathrm{~h}$. En aquellos casos en que se esperaba una carga inicial muy baja, se procedió a inocular $0,2 \mathrm{ml}$ de la primera dilución $\left(10^{-1}\right)$ en cinco placas de agar TCBS con el fin de obtener una mayor sensibilidad en el recuento. Después del periodo de incubación, se procedió a contar las colonias típicas para obtener el recuento.

Para llevar a cabo el experimento, se cepillaron los huevos con agua y jabón y se sumergieron en etanol al $95 \%$ por un minuto antes de abrirlos asépticamente. Se preparó una muestra compuesta de claras, vertiendo la clara de varios huevos en una bolsa estéril hasta obtener $130 \mathrm{~g}$, los cuales se homogenizaron en un Stomacher ${ }^{\circledR}$ durante dos minutos. Se tomaron 10 g de la muestra compuesta y se determinó la carga natural presente de V. mimicus.

La muestra restante (120 g) se dividió en dos: una mitad fue inoculada $\left(2,5 \times 10^{4} \mathrm{UFC} / \mathrm{g}\right)$ y la otra no. Además, se preparó un control que consistió en colocar el mismo inóculo en $60 \mathrm{ml}$ de APA $(\mathrm{pH} \mathrm{8,6).}$

Tanto la muestra inoculada, la muestra sin inocular y el control en APA se mantuvieron a $25^{\circ} \mathrm{C}$ en una incubadora (Freas 815) durante 18 h y se tomó una 
muestra de $10 \mathrm{~g}$ para cada una de ellas al inicio $(\mathrm{t}=0 \mathrm{~h})$ y al final $(\mathrm{t}=18 \mathrm{~h})$. A cada muestra $(10 \mathrm{~g})$ se le realizó el recuento de $V$. mimicus con el fin de determinar si existía algún efecto inhibitorio sobre el microorganismo. Se siguió el mismo procedimiento para realizar el estudio de sobrevivencia en una muestra compuesta de yemas. En ambos casos se trabajaron tres repeticiones independientes.

Se calcularon las diferencias entre el recuento final y el recuento inicial (incremento) para la muestra inoculada, sin inocular y para el control, tanto para la sobrevivencia en clara como en yema y mediante el programa estadístico SPSS 8.0 para Windows, se realizó un análisis de varianza con el fin de determinar la significancia del efecto simple (tiempo de incubación), utilizando como variable dependiente el incremento observado. Además, cuando el efecto simple fue significativo, se compararon las reducciones observadas en la clara o yema inoculada y sin inocular contra el control en APA, mediante la prueba de contrastes ortogonales. También se comparó la reducción observada para la clara o yema sin inocular contra la observada para la clara o yema inoculada.

\section{RESULTADOS Y DISCUSIÓN}

Los resultados para el control, así como para las claras inoculadas y sin inocular se muestran en el Cuadro 1. El control en APA representa un medio de cultivo apropiado en el cual la bacteria puede crecer y reproducirse, por lo que es el parámetro de comparación. Se puede observar que en las tres muestras hubo crecimiento del $V$. mimicus después de $18 \mathrm{~h}$. En el

Cuadro 1. Promedio de los incrementos observados, después de $18 \mathrm{~h}$ a $25^{\circ} \mathrm{C}$, para las diferentes muestras en el estudio de sobrevivencia del $V$. mimicus en la clara del huevo de tortuga lora (L. olivacea). Universidad de Costa Rica, San José, Costa Rica. 2000.

\begin{tabular}{lc}
\hline Muestra & $\begin{array}{c}\text { Incremento promedio }\left(\log _{10}\right. \\
\text { UFC/g) }\end{array}$ \\
\hline Clara sin inocular & 4,67 \\
Clara inoculada & 5,24 \\
Control APA & 5,49 \\
\hline
\end{tabular}

análisis de varianza realizado no se obtuvo diferencia en el crecimiento observado ( $\mathrm{p}=0,075)$, por lo que la clara del huevo de tortuga no es inhibitoria para el $V$. mimicus, por el contrario, resulta un medio de cultivo tan efectivo como el APA.

Los resultados anteriores difieren completamente de lo reportado en la literatura para la clara del huevo de gallina. Según afirman Frazier y Westhoff (1993), la clara del huevo es un medio inapropiado para el crecimiento de muchos microorganismos por diversos factores entre los que se encuentra: la apoproteína, la avidina, factores antiproteolíticos e inhibidores enzimáticos, la conalbúmina, la lisozima y el elevado $\mathrm{pH}$ que se alcanza durante el almacenamiento. Todos los factores mencionados anteriormente son proteínas (Belitz 1988) que representa un 10,6\% de la clara del huevo de gallina, mientras que en la clara del huevo de tortuga el contenido de proteína representa un 1,27\% (Mora 1995).

Aún cuando en el huevo de tortuga existieran estos factores, la baja concentración de los mismos podría explicar por qué no se presenta el efecto inhibitorio. Con respecto al pH, según Mora (1995), el valor más alto reportado para la clara del huevo de tortuga es de un 8,20 comparado con valores de hasta 9,40 para el huevo de gallina (Belitz 1988), y se encuentra en el rango de $\mathrm{pH}$ óptimo para el crecimiento de los vibrios (Barua 1992). Además, la lisozima actúa principalmente contra microorganismos Gram-positivos (Hughey et al. 1989), por lo que no tendría ningún efecto contra el V. mimicus.

En el caso de la prueba de sobrevivencia en yema los tratamientos estudiados fueron los mismos que en la prueba con la clara. Los resultados se presentan en el Cuadro 2. Tanto en la muestra inoculada como en el control en APA hubo crecimiento del V. mimicus. Al igual que en la prueba con la clara, no hubo diferencia significativa $(\mathrm{p}=0,170)$ en el incremento observado para la muestra inoculada y el control en APA, por lo que la yema también constituye un medio apropiado para la reproducción de la bacteria. En el caso de la muestra sin inocular, la ausencia de crecimiento puede explicarse por la menor probabilidad de que la yema se contamine con la flora de la cáscara al abrir el huevo, ya que no entra en contacto directo con ésta, contrario a lo que sí ocurre con la clara. 
Cuadro 2. Promedio de los incrementos observados, después de $18 \mathrm{~h}$ a $25^{\circ} \mathrm{C}$, para las diferentes muestras en el estudio de sobrevivencia del V. mimicus en la yema del huevo de tortuga lora (L. olivacea). Universidad de Costa Rica, San José, Costa Rica. 2000.

\begin{tabular}{lc}
\hline Muestra & $\begin{array}{c}\text { Incremento promedio } \\
\left(\log _{\mathbf{1 0}} \mathbf{U F C} / \mathbf{g}\right)\end{array}$ \\
\hline Yema sin inocular & 0,00 \\
Yema inoculada & 4,42 \\
Control APA & 5,21 \\
\hline
\end{tabular}

Los resultados de sobrevivencia en yema sí coinciden con el comportamiento en la yema del huevo de gallina que se considera un medio rico con gran cantidad de nutrientes necesarios para un adecuado desarrollo del embrión (Belitz 1988). En el caso del huevo de tortuga, la composición de la yema no es excepción, pues permite un crecimiento adecuado del V. mimicus.

En síntesis, ni la clara ni la yema constituyen una barrera para el crecimiento de V. mimicus, por el contrario, representan un medio en el que su reproducción es favorable. Esto demuestra la necesidad de estudiar tratamientos que permitan eliminar el vibrio para garantizar la inocuidad de los huevos.

\section{AGRADECIMIENTO}

Agradecemos a la M.Sc. Elena Campos del INCIENSA por su aporte en la realización de esta investigación y por suministrar la cepa de Vibrio mimicus que fue utilizada.

\section{LITERATURA CITADA}

Acuña, R. 1980. Aspectos de la fase terrestre de la tortuga lora (Lepidochelys olivacea). Tesis M.Sc. en Biología. Universidad de Costa Rica, Escuela de Biología. San José. p. 115.

Acuña, M; Díaz, G; Bolaños, H; Barquero, C; Sánchez, O; Sánchez, L; Mora, G; Chaves, A; Campos, E. 1999. Sources of Vibrio mimicus contamination of turtle eggs. Applied and Environmental Microbiology 65 (1): 1-3.

Alam, M; Miyoshi, S; Yamamoto, S; Tomochika, K; Shinoda, S. 1996. Expression of virulence-related properties by, and intestinal adhesiveness of, Vibrio mimicus strains isolates from aquatic environments. Applied and Environmental Microbiology 62(10):3871-3874.

Barua, D. 1992. Cholera. New York. Plenum Publishing. p. 392.

Belitz, H; Grosch, W. 1988. Química de los alimentos. Acribia, Zaragoza. p. 1134.

Campos, E; Bolaños, H; Acuña, MT; Díaz, G; Matamoros, MC; Raventós, H; Sánchez, L; Sánchez, O; Barquero, C; Red Nacional de Laboratorios para cólera, Costa Rica. 1996. Vibrio mimicus diarrhea following ingestion of raw turtle eggs. Applied and Environmental Microbiology 62(4):1141-1144.

Chowdhury, M; Yamanaka, H; Miyoshi, S; Aziz, K; Shinoda, S. 1989. Ecology of Vibrio mimicus in aquatic environments. Applied and Environmental Microbiology. 55(8):2073-2078.

Frazier, W; Westhoff, D. 1993. Microbiología de los alimentos. 4.ed. Acribia, Zaragoza. p. 681.

García, V; Antillón, F. 1990. Aislamiento de vibrio enteropatógenos de bivalvos y cieno del Golfo de Nicoya, Costa Rica. Revista de Biología Tropical 38(2): 437-440.

Hackney, C; Dicharry, A. 1988. Seafood-borne bacterial pathogens of marine origin. Food Technology. 42(3):84-90.

Hughey, V; Wilger, P; Johnson, E. 1989. Antibacterial activity of hen egg white lysozyme against Listeria monocytogenes Scott A in foods. Applied and Environmental Microbiology 55(3):631-638.

Mora, R. 1995. Composición química del huevo de tortuga lora (Lepidochelys olivacea) y evaluación de su calidad física y microbiológica durante su almacenamiento. Tesis Lic. en Tecnología de Alimentos. Universidad de Costa Rica, Escuela de Tecnología de Alimentos. San José. p. 69.

AGRONOMÍA MESOAMERICANA 19(2): 261-266. 2008 
Sanyal, S; Huq, M; Neogi, P; Alam, M; Kabir, M; Rahaman, A. 1983. Vibrio mimicus as an etiologic agent of diarrhea and its pathogenesis. Indian Journal of Medical Microbiology 1:1-12.
Shandera, W; Johnston, J; Davis, B; Blake, P. 1983. Disease from infection with Vibrio mimicus, a newly recognized Vibrio species. Annals of Internal Medicine 99: 169-171. 